\title{
Impact of Virtual Simulation and Coaching on the Interpersonal Collaborative Communication Skills of Speech-Language Pathology Students: A Pilot Study
}

\author{
Jacqueline A. Towson Ph.D., CCC-SLP \\ University of Central Florida, jacqueline.towson@ucf.edu \\ Matthew S. Taylor Ph.D. \\ University of Central Florida, matthew.taylor@knights.ucf.edu \\ Jennifer Tucker PT, DPT, PCS \\ University of Central Florida, jennifer.tucker@ucf.edu
}

See next page for additional authors

DOI: doi.org/10.30707/TLCSD2.2Towson

Follow this and additional works at: https://ir.library.illinoisstate.edu/tlcsd

Part of the Interprofessional Education Commons, Scholarship of Teaching and Learning Commons, and the Speech Pathology and Audiology Commons

\section{Recommended Citation}

Towson, Jacqueline A. Ph.D., CCC-SLP; Taylor, Matthew S. Ph.D.; Tucker, Jennifer PT, DPT, PCS; Paul, Claire Ph.D., BCBA; Pabian, Patrick PT, DPT, SCS, OCS; and Zraick, Richard I. Ph.D., CCC-SLP (2018) "Impact of Virtual Simulation and Coaching on the Interpersonal Collaborative Communication Skills of Speech-Language Pathology Students: A Pilot Study," Teaching and Learning in Communication Sciences \& Disorders: Vol. 2: Iss. 2, Article 2.

DOI: doi.org/10.30707/TLCSD2.2Towson

Available at: https://ir.library.illinoisstate.edu/tlcsd/vol2/iss2/2

This Scholarship of Teaching and Learning Research is brought to you for free and open access by ISU ReD: Research and eData. It has been accepted for inclusion in Teaching and Learning in Communication Sciences \& Disorders by an authorized editor of ISU ReD: Research and eData. For more information, please contact ISUReD@ilstu.edu. 


\title{
Impact of Virtual Simulation and Coaching on the Interpersonal Collaborative Communication Skills of Speech-Language Pathology Students: A Pilot Study
}

\author{
Abstract \\ Communication between clinicians, teachers, and family members is a critical skill when addressing and \\ providing for the individual needs of patients. However, graduate students in speech-language pathology \\ (SLP) programs often have limited opportunities to practice these skills prior to or during externship \\ placements. The purpose of this study was to explore the use of virtual-reality based rehearsal with \\ coaching on the interpersonal collaborative communication skills of SLP graduate students when \\ delivering information regarding a singular patient to different stakeholders. Three graduate students \\ completing their third semester in a SLP program participated in the study. Each participant was provided \\ a clinical case scenario and asked to deliver recommendations related to the client's communication \\ abilities to a single adult avatar portraying either a parent, teacher, or pediatrician. This task was repeated \\ twice to allow assessment of performance across multiple trials. A brief reflection and coaching period \\ was provided between trials with the same avatar. All interactions were scored using the Situation, \\ Background, Assessment, Recommendation, and Communication (SBAR-C) tool. All participants \\ demonstrated improved communication skills between their first and second trial with each avatar as \\ measured by the SBAR-C. Social validity surveys with participants revealed that they found the \\ intervention to be valid and acceptable.
}

\section{Keywords}

Interpersonal Communication, Collaboration, Coaching, Virtual Simulation, Speech-Language Pathology, Clinical Skills Training

\section{Authors}

Jacqueline A. Towson Ph.D., CCC-SLP; Matthew S. Taylor Ph.D.; Jennifer Tucker PT, DPT, PCS; Claire Paul Ph.D., BCBA; Patrick Pabian PT, DPT, SCS, OCS; and Richard I. Zraick Ph.D., CCC-SLP 
Communication between clinicians, teachers, and family members is a critical skill when addressing and providing for the individual needs of patients (Newton, Billett, Jolly, \& Ockerby, 2009). Interpersonal collaborative communication skills are critical for healthcare professionals in order to be able to accurately and effectively communicate with a variety of stakeholders and convincingly articulate the value of their services (Lubinski \& Golper, 2007). However, graduate students in speech-language pathology (SLP) programs rarely have opportunities to develop these skills prior to or during externship placements. Clinical educators report difficulty with effectively teaching interpersonal communication skills during a traditional clinical practicum (Picou \& Tharpe, 2015). Innovative and alternative models for clinical education are needed to allow students adequate opportunity to practice these clinical skills prior to their practicum placements and entering the workforce (Casares, Bradley, Jaffe, \& Lee, 2003; MacBean, Theodoros, Davidson, \& Hill, 2013, Rodger et al., 2008; Zraick, 2012).

\section{Interpersonal Collaborative Communication}

Interpersonal collaborative communication is an essential component of patient care in varying models of service delivery. Education experiences incorporating teachers and SLPs have been found to impact both knowledge and collaborative practice. (Miolo \& DeVore, 2016; Suleman et al., 2014). Miolo and DeVore (2016) found that interprofessional or collaborative educational experiences improved the skills of SLP students, specifically in collaborative consultation. In addition to gaining skills in collaborative consultation, Miolo and DeVore (2016) found students achieved "core interprofessional collaborative practice (ICP) competencies in the four domains of teams and teamwork, interprofessional communication, understanding roles and responsibilities, and values and ethics" (Miolo and DeVore, 2016, p. 81). Once students graduate and enter the workforce, they must possess professional interpersonal skills to work effectively as part of a team, allowing for others to implement and reinforce their interventions (Lubinski \& Golper, 2007). SLPs must be able to communicate effectively in both oral presentation of material as well as in written reports as this represents them as a professional to their collaborators and to the patients they serve (Lubinski \& Golper, 2007). Therefore, it is important graduate programs in SLP provide valid skill-acquisition opportunities for students that enable them to apply their academic knowledge effectively into 'real-world' clinical practice prior to entering the workforce (Newton et al., 2009), including the delivery of patient information to family members, educators, and physicians.

\section{Standardized Patients}

One model used to practice clinical skills, including communication, in the field of SLP, and in the medical and allied health professions field in general, has been the use of "standardized" or "simulated" patients (SPs). These are individuals that have been specifically trained to accurately portray a representation of a specific patient population (e.g., aphasia) according to educational need (Casares et al., 2003; Zraick, 2012). SPs are typically portrayed by an actor, whereas standardized patients are real patients; however, the terms are often used interchangeably (Bokken, Rethans, Scherpbier, \& van der Vleuten, 2008; Bressmann \& Eriks-Brophy, 2012). At one university, SLP students received a four-hour training to serve as standardized patients representing the disorders of spastic dysarthria secondary to cerebral palsy and aphasia due to stroke for a program designed to provide practice to varying medical professionals in patientprovider communication skills. Students were able to successfully provide practice to medical 
students and, in turn, learned more about the clinical populations they represented (Burns et al., 2017). Many benefits have been reported for the use of SPs, including comparability to real patients, faculty control of the learning experience, rehearsal of clinical situations students are not ready to manage alone, reduction of time demands on teaching faculty, reduction on learner anxiety, allows time for student reflection, and the ability to practice interpersonal skills (Picou \& Tharpe, 2015; Zraick, 2012). In a recent study by Baylor and colleagues (2017), SPs that were rated as believable by both SLPs and actual patients had multiple years of experience working as SPs and attended an additional six hours of training. Additionally, students in SLP and related health profession programs find the use of SPs an acceptable strategy (Bressman \& Eriks-Brophy, 2012; Burns et al., 2017; Hill, Davidson, \& Theodoros, 2013a; Zraick, Allen, \& Johnson, 2003).

While the use of SPs has shown promise in the training of students, there are also disadvantages, such as limited availability, time invested in training, and the variability in the learning experiences provided to students (Bokken, Rethans, Scherpbier, \& van der Vleuten, 2008; Hill, Davidson, \& Theodoros, 2010). Students also state that more preparation and detailed feedback is needed from both the SPs and their instructors when interacting with SPs (Bressman \& Eriks-Brophy, 2012). However, a recent study by Hill, Davidson, and Theodoros (2013b) suggests that a small sample of four SPs showed moderate to high levels of accuracy and consistency in representing a parent of a child with a speech disorder, following nine hours of specific training, as judged by three expert raters. This data represented SPs across three scenarios (i.e., parent interview for case history) and 22 SLP student interviews suggesting reproducibility and replicability (Hill et al., 2013b). Another disadvantage of using SPs is the time invested in training them to interact fully in character in any situation and the lack of availability to SPs across university settings (Picou \& Tharpe, 2015). Finally, there is limited research utilizing SPs to develop interpersonal collaborative communication skills.

There is a need to enhance the use of SPs in ways that allow for greater availability and standardization in a safe, controlled, learner-centered environment, combined with detailed feedback and coaching from clinical instructors. Virtual simulation may be a viable way to provided standardized clinical experiences across students in SLP programs as it allows for consistent interactions, opportunities for repetitive attempts for a targeted skill, and the opportunity for immediate feedback and multiple opportunities to self-correct (Dieker, Straub, Hughes, Hynes, \& Hardin, 2014; Taylor et al., 2017). Virtual simulation also minimizes or eliminates time invested in training, such as that needed for consistent performance with SPs.

\section{Virtual Simulation}

The use of virtual simulation is common in the preparation and continuing education of medical professionals and considered highly acceptable to its users with good generalizability of skills noted (Barsuk et al., 2012; Gordon, Wilkerson, Shaffer, \& Armstrong, 2001). In addition to training specific medical procedures, researchers have shown the specific use of virtual reality simulation and avatars was effective for medical professionals to practice delivering bad news to patients (Andrade, Bagri, Zaw, Roos, \& Ruiz, 2010). Similarly, in the field of physical therapy, researchers discovered that simulated rehearsal improved the confidence physical therapy students' communication skills with patients and other caregivers (Ohtake, Lazarus, Schillo, \& Rosen, 2013; Taylor et al., 2017). SLP programs in the U.S. and internationally recommended the use of virtual simulation, including virtual patients, in university clinical preparation programs 
(MacBean et al., 2013; Rodger et al., 2008).

Recently, the American Speech-Language Hearing Association (ASHA) made revisions to the Standards and Implementation Procedures for the Certificate of Clinical Competence in SpeechLanguage Pathology to allow for alternative clinical education (ACE) to account for up to $20 \%$ (i.e., 75 hours) of direct contact hours (ASHA, 2016). Therefore, graduate programs can now utilize simulation technologies to fill voids in clinical preparation. However, there is a dearth of empirical research in the use of virtual reality simulation for preparing graduate student clinicians, particularly in interpersonal collaborative communication.

While there is limited research in the use of innovative technologies, such as virtual simulation, to prepare graduate students in SLP, there is also great variability across studies. Virtual or computer generated patients were used by Strang and Meyers (1987) to simulate the speech of preschool children with dysfluency for the purposes of clinical training for parents and SLP students. Williams (2006) introduced interactive simulation technology for Communication Sciences and Disorders (CSD) students using an "immersive virtual reality" (IVR) and proposed use for training student clinicians in diagnostic procedures as well as for use with fluency clients to practice skills in simulated environments. While there appears to be limited published empirical research supporting the use of IVR, information presented at the 2009 ASHA Convention indicated there were no significant differences in graduate students' perceptions of using standardized patients in comparison to virtual human avatars (Williams, 2009). However, this singular study did not account for skills acquired by the students in the two conditions, and had a relatively small sample size of 77 participants, with only 11 participants in the field of SLP and the remaining being dental students (Williams, 2009). Williams (2009) also reported that first year SLP graduate students performed significantly higher in virtual learning environments when provided with strong faculty support, suggesting the need for coaching and guidance to most effectively use virtual reality simulation. Finally, students that engaged in several interactions with the virtual program scored significantly higher than those interacting only one or two times, again suggesting the need for repeated practice for students (Williams, 2009).

In subsequent literature, Williams and Schreiber (2010) describe the use of virtual simulation, using SimuCase ${ }^{\mathrm{TM}}$, a web-based virtual simulation application to prepare graduate SLP students in real-world clinical experiences. SimuCase ${ }^{\mathrm{TM}}$ allows users to select a particular type of disorder and analyze client data, with the hopes of improving clinical decision making skills in the area of assessment (Williams \& Schreiber, 2010). These simulated experiences are thought to allow graduate students the ability to solve real-life problems in a way that cannot be done through traditional teaching methods.

TeachLivE ${ }^{\text {TM }}$. In the area of teacher preparation, Dieker, Hynes, Hughes, and Smith (2008) developed an innovative technology, TeachLivE ${ }^{\mathrm{TM}}$, to instruct pre-service teachers through the use of virtual reality simulation. The TeachLivETM simulator is a mixed reality experience that immerses the participants in a multi-student classroom or in a one-on-one conference setting, using avatars that respond in real-time and are controlled by an interactor (Straub, Dieker, Hynes, \& Hughes, 2014). This technology allows professors to develop engaging lessons with hands-on experience to allow students to practice skills to a greater degree prior to interacting with school- 
age students in real time settings (Andrade et al., 2010; Straub et al., 2014). Empirical studies on TeachLivETM suggest that it is a viable, innovative tool to allow pre-service teachers the opportunity to interact with avatars to improve pedagogical skills, while receiving guidance from professors that are generalizable to the regular classroom (Straub et al., 2014; Straub, Dieker, Hynes, \& Hughes, 2015). In the field of education, TeachLivETM has been used to target a wide variety of skills, such as asking open-ended questions, accessing higher-order thinking skills, providing opportunities for students to respond, functional analysis, and parent conferencing (Straub et al., 2014, 2015, 2016; Vasquez, Marino, Donehower, \& Koch, 2017).

\section{Purpose}

The purpose of this study was to explore the use of virtual-reality simulation and coaching on the interpersonal collaborative communication skills of SLP graduate students when delivering information regarding a singular patient (i.e., case study) to different stakeholders (i.e., parent, teacher, pediatrician) using the TeachLivETM virtual simulator. The research questions were: (1) To what extent does the combination of virtual simulation using the TeachLivE ${ }^{\mathrm{TM}}$ simulator and coaching between two opportunities to deliver clinical information and recommendations regarding a singular patient to a virtual avatar who is successively a (a) parent, (b) teacher, and (c) pediatrician affect the communication skills of graduate SLP students? (2) What is the social validity of using the TeachLivE ${ }^{\mathrm{TM}}$ simulator from the perspective of the graduate students?

Currently, there are no documented studies in the area of SLP that have evaluated the effects of using a real-time virtual simulator to build graduate students' interpersonal collaborative communication skills. Research supports the benefit of collaborative educational experiences (Miolo \& DeVore, 2016; Suleman et al., 2014) using face to face experiences. However, based on clinical experience, it is thought that while graduate SLP students will deliver the information accurately, they will not significantly vary in their delivery of information between three singular avatar experiences of parent, teacher, and child. Following coaching sessions in between two sessions with a single avatar, it is hypothesized that participants will improve their communication skills. Finally, it is expected that participants will find these interactions using the TeachLivE ${ }^{\mathrm{TM}}$ simulator to be beneficial to their learning experiences.

\section{Method}

\section{Research Design}

This pilot study was developed using the TeachLivE ${ }^{\mathrm{TM}}$ simulator to observe participants' (i.e., SLP students) interactions with an avatar playing the role of a physician, teacher, and parent. The researcher employed a single group pretest/posttest design to investigate the effect of the TeachLivE ${ }^{\mathrm{TM}}$ simulator on the communication skills of the participants. Data was collected using a pretest/posttest measure (i.e., Situation, Background, Assessment, Recommendation, and Communication tool) to assess any change in the participants' communication skills from pretest to posttest and to provide coaching to participants after each interaction with each communication partner. 


\section{Setting}

All sessions were conducted in the TeachLivE ${ }^{\mathrm{TM}}$ lab on the campus of a large university campus in the Southeastern United States. This lab has a large television screen, which features a virtual conference room and one adult avatar. There is a desk and chair in front of the screen in which the participant sits, with additional chairs around the perimeter of the room for observers. The avatar used for this study was an adult female representing three distinct people (i.e., parent, teacher, and pediatrician).

\section{Participants}

Three participants from one graduate program in CSD (i.e., SLP) were recruited for this study. Students were completing their third of six semesters in the program and were currently enrolled in a Diagnostic Lab Seminar. All three participants were female and in their early twenties. Two reported having undergraduate degrees in CSD, with the third having an undergraduate degree in psychology.

\section{Inter-raters}

The primary scorer for this study was a faculty member with certifications in both SLP and special education. The inter-rater for this study was a doctoral student with eight years of teaching experience in general and special education as well as extensive experience working with parents, teachers, related service providers, and medical professionals. Both raters scored and provided coaching to all participants during all sessions.

\section{Patient Case Description}

The patient case description was designed to convey a clinical scenario students might encounter in their practice. The case described a 13-year-old girl with a recent traumatic brain injury (TBI). The case description included information on accident that caused the TBI, the patient's current medical condition, and recovery timeline. The participants were expected to know and understand the terms detailing the patient's condition in the case description. A reference sheet detailing key terms used in the field was provided for the interactor. (See Appendix A and B for the case study provided to the students as well as the interactor protocol.)

\section{Procedures}

Each participant was provided with the patient case description approximately 24 hours prior to their scheduled session. Upon arrival, each participant was supplied with a copy of the patient case description to reference (if needed) and was oriented to the TeachLivE ${ }^{\mathrm{TM}}$ simulator. One of the researchers demonstrated how to begin the simulation, interact with the avatar, and pause or end the simulation. Researchers provided a description of how the 60 minute session would run. The participant interacted with the adult avatar (portraying the parent, teacher, or physician) a total of six times during the 60 minute session (see Table 1). During each interaction, the participant was asked to provide information to each communication partner about the patient's condition and 
provide an appropriate recommendation. The avatar portrayed realistic responses to the recommendations and engaged in a dialogue with participants. The virtual simulation experience provided opportunities for interpersonal communication and collaboration. Each participant engaged in an initial interaction lasting five minutes followed by a period of participant reflection and observer coaching lasting five minutes, and then a second interaction with each communication partner lasting five minutes followed by a period of participant reflection and observer coaching lasting five minutes (see Table 1). Reflection by the students was based on their memory of the interaction, as they were not provided with a video playback of the interactions. This sequence was repeated three times in total: once with the avatar as the parent, once with the avatar as the teacher, and once with the avatar as the physician. The physical appearance of the avatar did not change; however, participants were reminded of the identity of their communication partner at the beginning of each interaction.

Table 1 Example of Participant Session (Taylor et al., 2017)

\begin{tabular}{|c|c|}
\hline Segment & Interaction Time (mins) \\
\hline \multicolumn{2}{|l|}{ Session 1 (Parent) } \\
\hline Interaction with Avatar (First) & 5 \\
\hline Reflection/Coaching & 5 \\
\hline Interaction with Avatar (Second) & 5 \\
\hline Reflection/Coaching & 5 \\
\hline Total Interaction Time & 20 \\
\hline \multicolumn{2}{|l|}{ Session 2 (Teacher) } \\
\hline Interaction with Avatar (First) & 5 \\
\hline Reflection/Coaching & 5 \\
\hline Interaction with Avatar (Second) & 5 \\
\hline Reflection/Coaching & 5 \\
\hline Total Interaction Time & 20 \\
\hline \multicolumn{2}{|l|}{ Session 3 (Medical Professional) } \\
\hline Interaction with Avatar (First) & 5 \\
\hline Reflection/Coaching & 5 \\
\hline Interaction with Avatar (Second) & 5 \\
\hline Reflection/Coaching & 5 \\
\hline Total Interaction Time & 20 \\
\hline Total Time in Simulator & 60 \\
\hline
\end{tabular}

\section{Independent Variables}

TeachLivE ${ }^{\mathrm{TM}}$ virtual simulator. TeachLivE ${ }^{\mathrm{TM}}$ is a mixed reality simulator that immerses participants in classroom-based or one-on-one interactions with student or adult avatars who are controlled by an interactor and able to respond in real-time (Straub et al., 2014). The simulator was originally developed to provide pre-service teachers the opportunity to practice pedagogical and content area skills by immersing them in a virtual classroom with student avatars. Straub and colleagues $(2014,2015)$ completed two studies using the TeachLivE ${ }^{\mathrm{TM}}$ simulator using the middle 
school and high school virtual classroom environments. The researchers found over four 10-minute sessions in the simulator with guided reflection from a facilitator, participants were able to learn and retain target skills. The TeachLivE ${ }^{\mathrm{TM}}$ simulator serves as a safe and controlled environment for teachers and other clinicians to practice their craft and receive immediate feedback (Dieker et al., 2014; Nagendran, Pillat, Kavanaugh, Welch, \& Hughes, 2014; Ohtake et al., 2013). The use of the simulator has expanded to include adult-to-adult interactions (e.g., parent-teacher conferences, co-teaching meetings). The adult avatar can represent an employer, parent, teacher, or other professional and was developed to specifically target professional skills, such as interviewing, parent-teacher conferences, individualized education program meetings, and jobcoaching (Straub et al., 2016).

In this research study, the participants interacted with the adult avatar to practice appropriate and effective interpersonal collaborative communication with a parent, teacher, and physician. The participant sat at a small desk while interacting with the avatar on the large television screen. The avatar was an adult female who appeared to be in a conference room setting (Hamstra, Brydges, Hatala, Zendejas, \& Cook, 2014). While the avatar's appearance remained the same in each interaction, her tone of voice, language, posture, and content changed dramatically for each character (i.e., parent, teacher, and physician). For example, when portraying the parent, the avatar was emotional and struggled to process the recommendations. In contrast, when portraying the teacher, the avatar was poised, knowledgeable of educational recommendations, and collaborative when working with the participant. Last, when the physician was portrayed, the discussion focused on clinical decision-making and coordination of care. A web-camera allowed the interactor to see the participant and react to their verbal and nonverbal communication. Participants were able to pause or stop the simulation at any time to ask questions or take a break.

Interactor. TeachLivE ${ }^{\mathrm{TM}}$ is a virtual environment where participants can interact with avatars in real time. The avatar is controlled by an interactor who is situated in a different room. All interactors have a background performing arts and improvisation and go through an extensive orientation and training process.

The interactor for the TeachLivE ${ }^{\mathrm{TM}}$ simulator was given the patient case description two weeks before the study began. In addition, the interactor, a faculty member in communication sciences, and the special education teacher met to review the case description, target skills, expectations, and address any questions. The interactor was provided with suggested responses and reactions based on the potential behaviors and comments from the participants. Participants were provided with the patient case description approximately one day prior to their scheduled session in the simulator. Both the interactor and participants were instructed the conversation should focus on recommendations for speech-language therapy services in a school-based setting.

Coaching. Following each initial interaction with a given avatar, participants were asked to reflect on their interaction. Verbal face-to-face feedback was provided by the two inter-raters related specifically to the SBAR-C tool (see Appendix C). For example, if the participant did not introduce themselves or explain their role to the avatar, it was suggested they do so on the subsequent attempt. Participants were provided with paper and pen to take notes during the coaching component, although it was not required. 


\section{Dependent Variables}

Situation, Background, Assessment, Recommendation and Communication tool (SBAR-C). Each interaction in the TeachLivE ${ }^{\mathrm{TM}}$ simulator was scored using a modified version of the Situation, Background, Assessment, and Recommendation (SBAR) tool (Trentham, Andreoli, Boaro, Velji, \& Fancott, 2010). The SBAR was created to help evaluate and facilitate better communication among healthcare professionals and patients. For the purposes of this study, a modified version was used, taken from a similar study involving physical therapy students (Taylor et al., 2017). The first section of the tool, "Situation," requires the participants to present themselves, their role in the discussion, and the purpose of the meeting. In the second section, "Background," the participants share any relevant information regarding the patient's injury and current treatment. The third section, "Assessment," requires participants to clarify any of the patient's current issues or needs. Finally, in the "Recommendation" section, the participant has an opportunity to summarize the discussion and provide next steps for the patient. Marshall, Harrison, and Flanagan (2009) evaluated the SBAR tool for clarity and content in professional communication and found the tool to be reliable (as measured by Cohen's Kappa; mean = 0.88).

As previously mentioned, the SBAR was originally designed to measure effective communication between medical professionals. Because this study specifically addresses communication between a professional and a parent or caregiver, a fifth category was added labeled "Communication." In this section of the rubric, participants were assessed on their ability to use situation appropriate language and demonstrate affective behaviors congruent with the values and needs of their communication partner (i.e., parent, teacher, physician) (Graham-Clay, 2005; Verlinde, De Laender, De Maesschalck, Deveugele, \& Willems, 2012). The addition of the "Communication" category was made by Taylor and colleagues (2017) to support their study with physical therapy students and TeachLivETM.

Inter-observer Agreement (IOA). Each interaction was scored by two observers (i.e., SLP and special educator) for fidelity purposes. Both observers provided the participant with coaching, including recommendations after each interaction was completed. Interobserver agreement (IOA) was calculated across the three participants. Based on the total of 18 possible interactions rated by the first rater, a random number generator determined $30 \%$ of the data to be analyzed for IOA by a second independent rater. Comparisons were calculated by determining the total number of agreement divided by the total number of agreements and disagreements for an IOA of $67 \%$. The two raters reviewed the videos with discrepancies and discussed disagreements and agreed on a score. The majority of the discrepancies were based on the degree to which a behavior was observed, not the presence or absence of a behavior. However, the original scores of the first rater were used for the data reported.

Social Validity. Following interaction with each of the three avatars, each participant completed a social validity rating scale adapted from the Abbreviated Acceptability Rating Profile - Modified (AARP-M; Tarnowski \& Simonian, 1992). Participants ranked each of the seven items using a six point Likert scale ( $1=$ strongly disagree, $6=$ strongly agree $)$. Questions related to the acceptability and effectiveness of TeachLivE ${ }^{\mathrm{TM}}$ for teaching professional communication, willingness to 
participate in future interactions using virtual simulation, and the presence of negative side effects (see Appendix D for specific items).

\section{Results}

Each participant was assigned a random order to interact with the avatar representing the three audiences as to diminish the possibility of a maturation effect. Participant 1 interacted first with the avatar as a physician, then as a teacher, and finally as a parent. Participant 2 and Participant 3 interacted with the physician first, then parent, and lastly the teacher. Participants were scored using the SBAR-C rubric by the first author using real-time coding as the participants engaged with each of the avatars. The second author also coded each participant, however, only $30 \%$ of the data was retained for calculation of IOA. Trends in data are reported descriptively within and across participants and can be found as a histogram in Figures 1-4. All participants demonstrated improvements between interactions with the avatar.

\section{Participant 1}

Participant 1 (P1) showed improvements during her interactions with the avatar as all three audiences. The first two attempts were with the avatar as a physician. During the first attempt with the physician, P1 conveyed a satisfactory (one point) level of information regarding the Situation (S) and Communication (C), but failed (zero points) to convey the background (B), assessment (A), and provide recommendations (R). After reflection and coaching, P1's scores with the physician improved for all SBAR-C components, except providing adequate background (B) information to the avatar. With the parent avatar, P1's total scores on the SBAR-C improved in every category from satisfactory (one point) to appropriate (two points) between interactions. The final interaction was with the avatar representing a teacher. P1 satisfactorily explained the situation $(\mathrm{S})$, background $(\mathrm{B})$, recommendation $(\mathrm{R})$, and communication $(\mathrm{C})$ components, but failed to provide an assessment (A). In the second attempt with the teacher, P1 demonstrated increase in scores on each of the SBAR-C categories (see Figure 1). Upon completion of all interactions, P1 said she found the doctor the hardest to interact with, as she had to make sure her vocabulary was accurate. She also commented, "[TeachLivETM] is such a cool thing... I felt way better by the end than I did at first." 


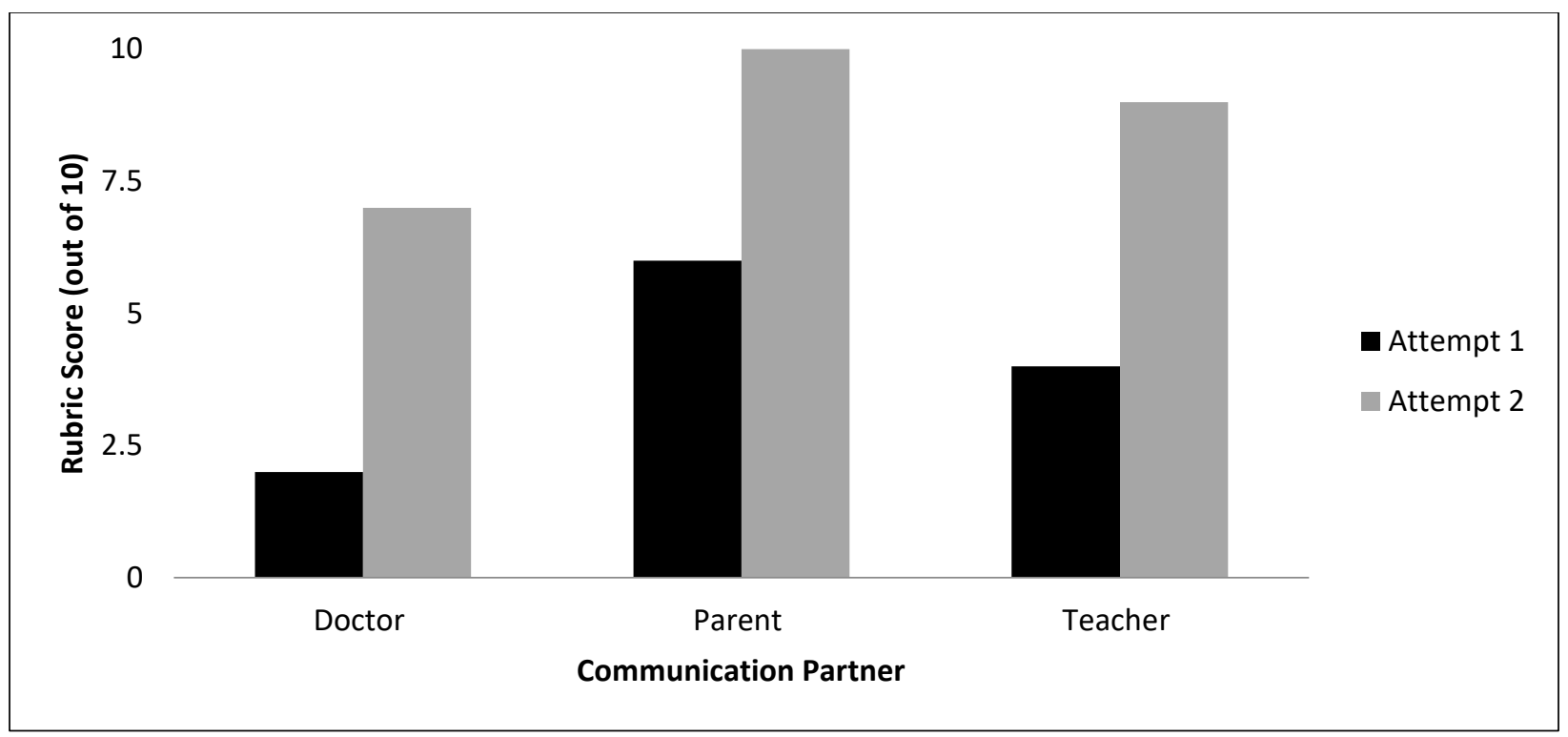

Figure 1. Participant 1: Average SBAR-C Score by communication partner.

\section{Participant 2}

Participant 2 (P2) interacted with the avatar first as a parent, then teacher, and finally as a physician. She was able to improve scores with two of her three opportunities with the avatar. In the first interaction with the physician, P2 satisfactorily described the situation (S), background (B), and gave recommendations (R), but failed to convey assessments (A) and an appropriate level of communication (C). After reflection and coaching, her second interaction was similar to the first, increasing in providing recommendations $(\mathrm{R})$ and adequately communicating $(\mathrm{C})$ to the physician, but decreasing in other areas of the rubric. The next interaction was with the avatar as a teacher. P2 began this interaction providing appropriate information regarding the situation $(\mathrm{S})$ and satisfactorily providing background and recommendations. P2 failed to provide assessment (A) information and appropriate communication (C) style. The second attempt with the avatar as a parent brought increases in all areas, including appropriate communication (C) and description of the situation, as well as satisfactory explanation of the background, assessment, and recommendations. The final interactions for $\mathrm{P} 2$ were with the avatar as a parent. During the first attempt with the parent avatar, P2 satisfactorily presented the situation (S) and recommendations (R), but failed to provide background (B) and assessment (A) information with an appropriate communication (C) style. All scores improved to either excellent or satisfactory during P2's second attempt with the parent (see Figure 2). P2 stated she had no experience in this kind of setting and found the teacher hardest to interact with due to facial expressions and tone, but "I wish I had [TeachLivETM] at home so that I can practice." 


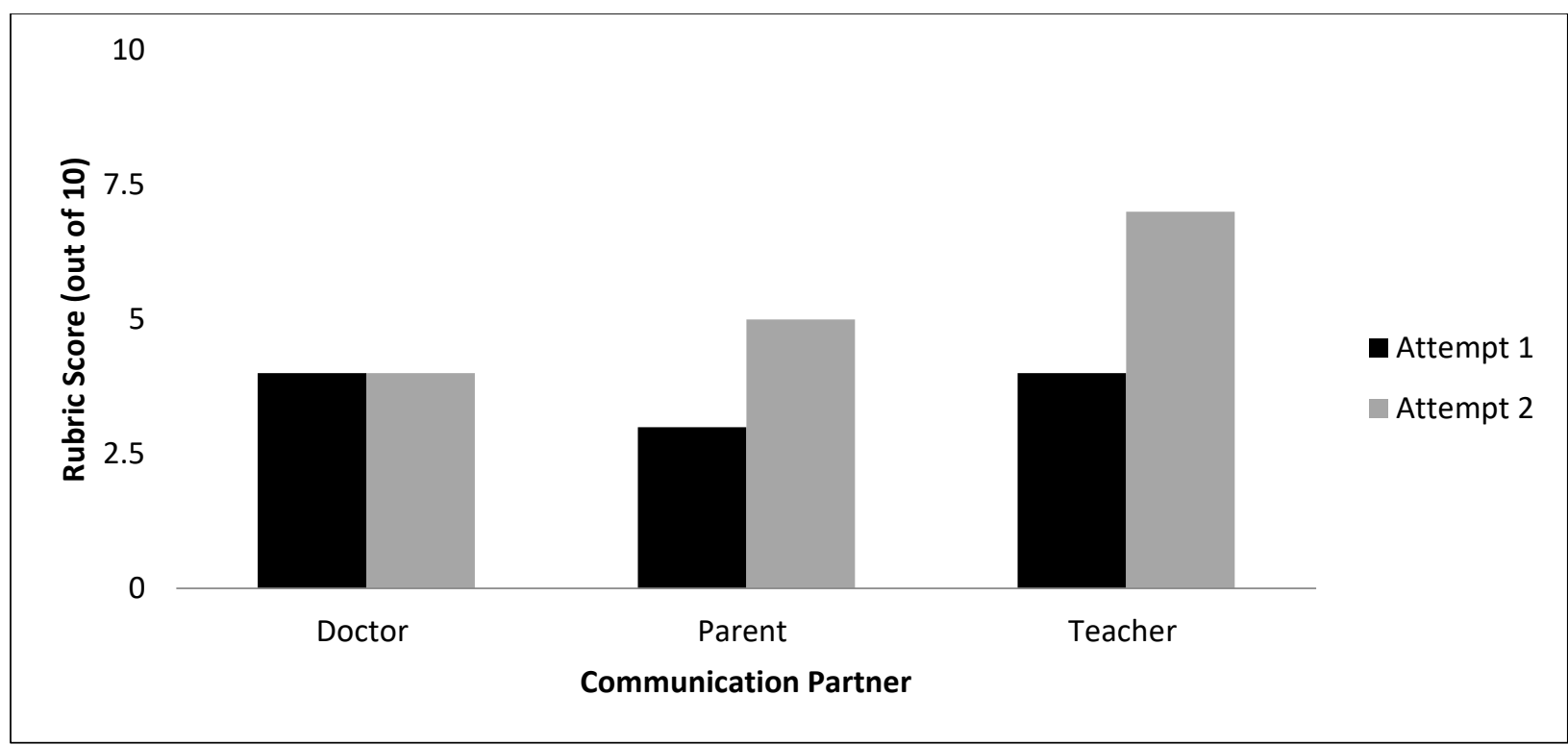

Figure 2. Participant 2: Average SBAR-C Score by communication partner.

\section{Participant 3}

The interactions for Participant 3 (P3) were presented as teacher, physician, and finally parent. During all interactions, P3 appropriately communicated (C) with the avatar. In the first attempt with the physician, she appropriately presented the situation $(\mathrm{S})$ and satisfactorily described the background (B) and assessment (A). The recommendations (R) were not mentioned during this attempt. The second time through with the physician, P3 appropriately gave information regarding the situation (S) and recommendations (R), and satisfactorily discussed background (B) and assessment (A). The second interaction was with the teacher and during the first attempt the situation (S), background (B), and recommendations (R) were satisfactorily discussed, but information regarding assessments (A) was not included. P3 improved scores during the second interaction in providing background (B) and assessment (A) information, and remained satisfactory regarding situation $(\mathrm{S})$ and recommendations $(\mathrm{R})$. The final interactions were with the avatar as the parent. P3 appropriately described the situation (S) and satisfactorily described the assessment (A) and recommendations (R), but failed to provide background (B) information. During the final attempt with the parent avatar, P3 improved all scores to appropriate, except failed to provide assessment (A) information (see Figure 3). P3 stated she had no prior experience with a simulator like TeachLivE ${ }^{\mathrm{TM}}$ and found interactions with the physician the most difficult. 


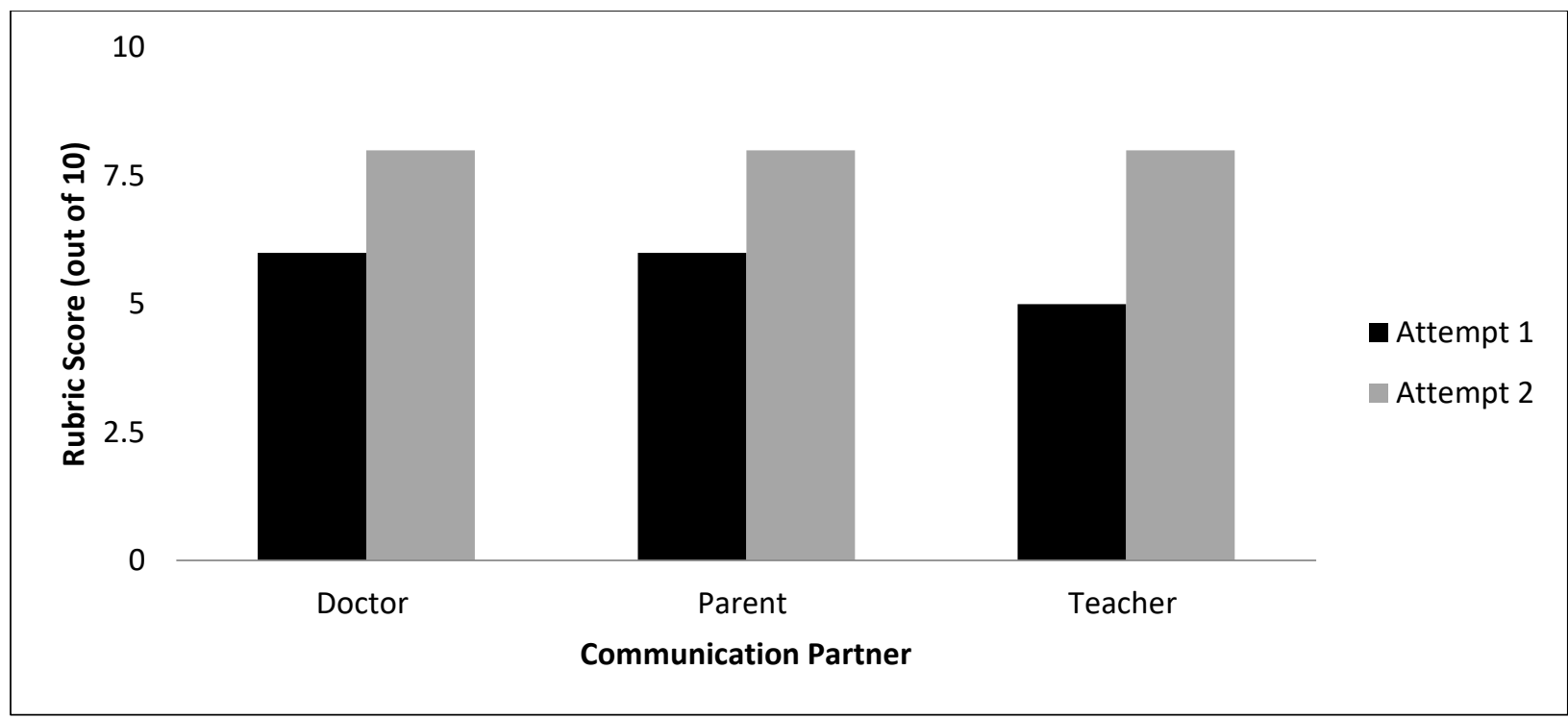

Figure 3. Participant 3: Average SBAR-C Score by communication partner.

\section{Summary of Participants}

All participants showed improvement on their second attempt with each of the three avatars (i.e., doctor, parent, teacher) following a brief period of reflection and coaching. The participants scored highest on the SBAR-C for the parent on the initial interaction, followed by the teacher and then the doctor. However, the greatest improvement across participants was noted for the teacher interactions and the least improvement for the doctor (see Figure 4).

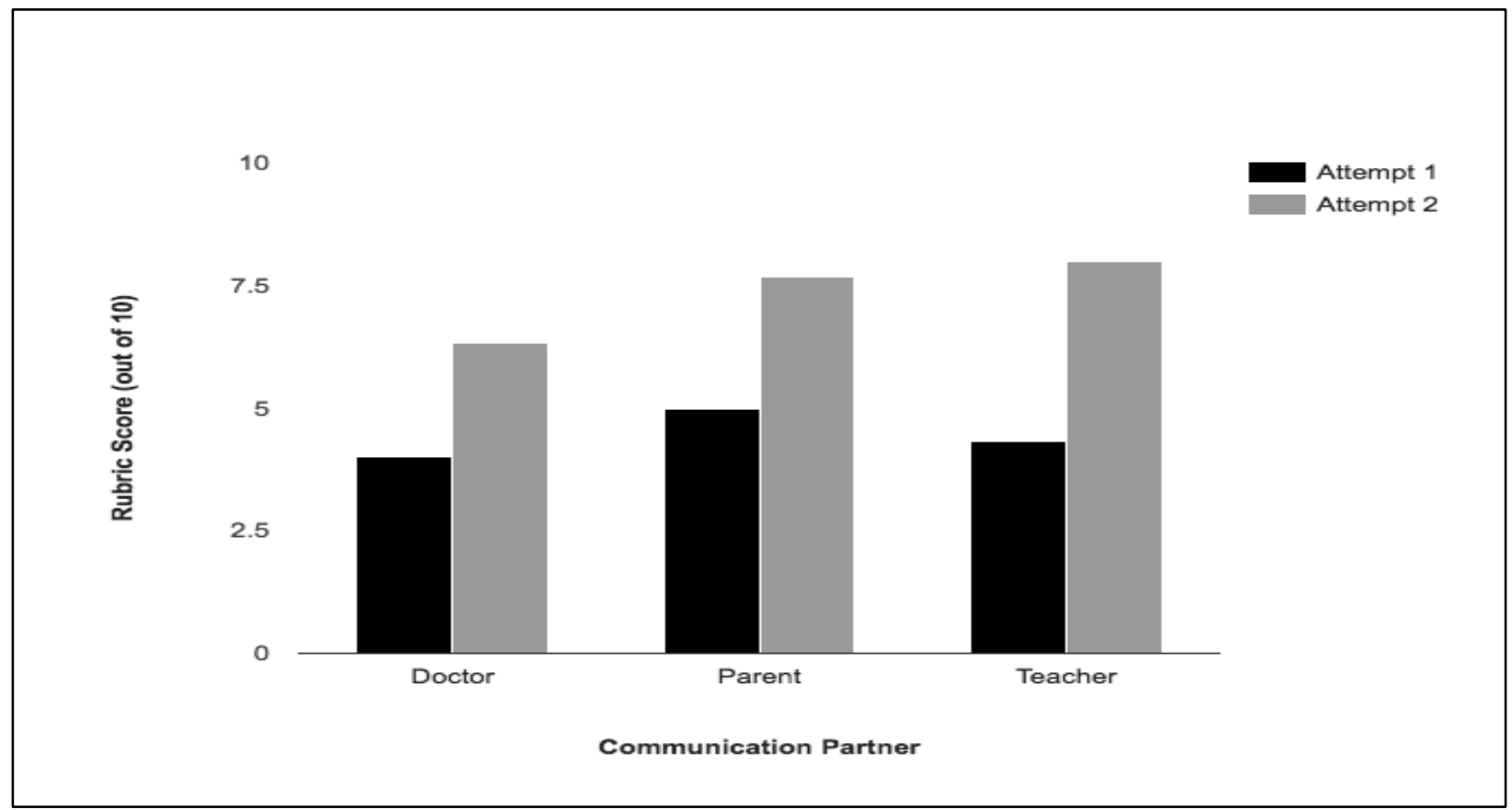

Figure 4. Average SBAR-C Score across participants by communication partner. 


\section{Social Validity}

Across all seven indicators the mean total score across the three participants was 38.3 out of a possible 42 points, with each individual question meeting or exceeding an average of 4.3 on a sixpoint scale. Specific question means were as follows: 5.3 (acceptability of strategy), 6.0 (effectiveness of strategy), 6.0 (willingness to use strategy in future), 4.3 (strategy will not have negative side effects), 5.3 (liked strategy), 5.3 (good teaching strategy), and 6.0 (helpfulness of strategy).

\section{Discussion}

Virtual simulation is a method for SLP students to acquire interpersonal collaborative communication skills before entering professional practice. Recent revisions in ASHA clinical hours for graduate students allows instructors and students to work in simulated environments to hone their abilities (ASHA, 2016). Recommendations have been expanded to include an emphasis on interprofessional, collaborative education in preparation for collaborative practice (ASHA, 2016). The purpose of this study was to evaluate the combined effects of virtual simulation and coaching on the interpersonal collaborative communication skills of SLP graduate students when delivering information regarding a singular patient to different stakeholders (i.e., parent, teacher, pediatrician) using a virtual simulator (i.e., TeachLivE ${ }^{\mathrm{TM}}$ ).

All three participants were able to improve scores on the SBAR-C from their first interaction with the avatar as a specified audience (i.e., parent, teacher, or pediatrician) given the opportunity for self-reflection and coaching. Similar results were found by Taylor and colleagues (2017) while researching physical therapy graduate students' communication skills using a virtual simulator to deliver information to three audiences. However, Taylor and colleagues (2017) found physical therapy participants were more comfortable during interactions in which the avatar represented a medical professional, while SLP participants in the current study did not feel the same way.

On average, participants performed the best when interacting with the teacher and least when interacting with the physician. Parent interaction ratings were very similar to that of the teacher. The researchers expected participants to be most comfortable with the physician, as the vernacular is similar to their studies. The results did not support this expectation, and may be attributed to SLP students receiving more experiences with parents in the clinical setting, while experience with physicians occurring later in internship placements or not at all.

Improvement was noted for all three participants in their overall SBAR-C ratings following a brief coaching session between opportunities to interact with each of the three avatars. P1 and P3 showed the most improvement, with P2 showing the least amount of change (see Figure 4). Across participants, the greatest improvement was noted for the teacher interactions and the least improvement for the doctor. While P1 showed significant improvement with the physician interaction, P2 showed no improvement, and P3 limited improvement. This may be attributed to the lack of interaction the SLP students at this institution receive during in-house clinical

placements. Further research should explore the introduction of interpersonal collaborative communication related specifically to medical professionals across graduate programs in CSD. 
All three participants rated the acceptability and effectiveness of TeachLivE ${ }^{\mathrm{TM}}$ as high. This is consistent with prior literature where virtual simulation was rated as acceptable and effective to practice the delivery of bad news to patients in the fields of both medicine and physical therapy (Andrade et al., 2010; Barsuck et al., 2012; Gordon et al., 2001; Ohtake et al., 2013; Taylor et al., 2017). Participants in this study gave the highest rating (six out of six across all participants) in the areas of effectiveness, acceptability and willingness to use the strategy in future clinical preparation. The lowest rating was related to the intervention having potential negative side effects, with $\mathrm{P} 2$ rating TeachLivE ${ }^{\mathrm{TM}}$ as a two out of six. This particular participant opted to end the interaction early twice and appeared surprised by the realism of the simulation experience. Overall, virtual simulation (e.g., TeachLivE ${ }^{\mathrm{TM}}$ ) is one viable option to practice interpersonal collaborative communication skills, as this study provides preliminary evidence that it may be as effective as other modalities, as the acceptability rating were similar to studies using SPs (Bressman \& EriksBrophy, 2012; Burns et al., 2017; Hill et al., 2013a; Zraick et al., 2003). While there are similarities between virtual simulation technologies and SPs, such as the training of the interactor, the standardization of an avatar representation and the ease of access to the technology, may prove to provide students with more consistent and readily available opportunities to practice clinical skills. Virtual simulation has potential for expansion into other clinical areas for SLP graduate students, such as practicing interpersonal collaborative communication in meeting settings (e.g., individualized education program meetings) and delivering assessments and interventions to specific patient populations.

\section{Limitations and Future Implications}

The present findings are based on three participants, as the intent of this study was to explore the potential use of virtual simulation in one SLP graduate program. Future studies should increase the number of participants and allow for a comparison condition, such as that used in single case research design or group design studies. It would also be beneficial to include students from more than one university to increase generalizability of results. Participants received a one-hour session to practice interpersonal collaborative communication skills; it could be possible that more sessions would further improve these skills. Measures could also be expanded to capture some of the nuances regarding students' perceptions of the experience beyond a rating scale (i.e., openended social validity questions) as well as measures to capture students perceived self-efficacy skills and translation to clinical experiences.

Only one case study was used in this research study. As participants progressed through the sessions, they may have become more familiar with the case study, which could have possibly changed their delivery of the information. The researchers attempted to account for this maturation effect by randomly assigning the order the avatar was presented as three audiences to each participant (Taylor et al., 2017). Additionally, while the present study focused primarily on an educational setting, future research in virtual simulation could be expanded to other relevant setting for SLPs.

Interprofessional experiences, while beneficial, can be challenging to coordinate and implement. Varying health care profession and educational programs may be on different timelines and not at 
a similar point in training to practice specific collaborative practice skills, such as, interpersonal communication. TeachLivE ${ }^{\mathrm{TM}}$ may offer a readily available opportunity for collaborative educational experiences that may be incorporated into coursework throughout the curriculum.

\section{Conclusion}

Continued investigation of the use of virtual simulation to develop interpersonal collaborative communication skills and additional clinical experiences in the preparation of SLP graduate students is essential. With the recent approval by ASHA (2016) to allow for ACE to account for up to $20 \%$ (i.e., 75 hours) of direct contact hours, empirical data is needed to determine the types, frequency, duration, and supports necessary to use virtual simulation in the most effective ways. Furthermore, TeachLivE ${ }^{\mathrm{TM}}$ may be an effective teaching modality using simulation to create collaborative education experiences targeting skills in the different competencies for interprofessional collaborative practice.

\section{References}

American Speech-Language-Hearing Association. (2016). 2014 Standards and Implementation Procedures for the Certificate of Clinical Competence in Speech-Language Pathology. Retrieved from http://www.asha.org/Certification/2014-Speech-Language-PathologyCertification-Standards/.

Andrade, A. D., Bagri, A., Zaw, K., Roos, B. A., \& Ruiz, J. G. (2010). Avatar-mediated training in the delivery of bad news in a virtual world. Journal of Palliative Medicine, 13(12), 1415-1419.

Barsuk, J. H., Cohen, E. R., Caprio, T., McGaghie, W. C., Simuni, T., \& Wayne, D. B. (2012). Simulation-based education with mastery learning improves residents' lumbar puncture skills. Neurology, 79(2), 132-137.

Baylor, C., Burns, M. I., Struijk, J., Herron, L., Mach, H., \& Yorkston, K. (2017). Assessing the believability of standardized patients trained to portray communication disorders. American Journal of Speech-Language Pathology, 26(3), 791-805.

Bokken, L., Rethans, J. J., Scherpbier, A. J., \& van der Vleuten, C. P. (2008). Strengths and weaknesses of simulated and real patients in the teaching of skills to medical students: a review. Simulation in Healthcare, 3(3), 161-169.

Bressmann, T., \& Eriks-Brophy, A. (2012). Use of simulated patients for a student learning experience on managing difficult patient behavior in speech-language pathology contexts. International Journal of Speech-Language Pathology, 14(2), 165-173.

Burns, M., Baylor, C., Yorkston, K., Nordehn, G., Meredith, A., Bye, L., ... \& Pound, C. (2017). Patient-provider communication training for dysarthria: Lessons learned from student trainees. Seminars in Speech and Language, 38(3), 229-238.

Casares, G. S., Bradley, K. P., Jaffe, L. E., \& Lee, G. P. (2003). Impact of the changing health care environment on fieldwork education. Journal of Allied Health, 32(4), 246-251.

Dieker, L., Hynes, M., Hughes, C., \& Smith, E. (2008). Implications of mixed reality and simulation technologies on special education and teacher preparation. Focus on Exceptional Children, 40(6), 1.

Dieker, L. A., Straub, C. L., Hughes, C. E., Hynes, M. C., \& Hardin, S. (2014). Learning from 
virtual students. Educational Leadership, 71(8), 54-58.

Gordon, J. A., Wilkerson, W. M., Shaffer, D. W., \& Armstrong, E. (2001). "Practicing" medicine without risk: Students' and educators' responses to high-fidelity patient simulation. Academic Medicine-Philadelphia, 76(5), 469-472.

Graham-Clay, S. (2005). Communicating with parents: Strategies for teachers. School Community Journal, 15(1), 117.

Hamstra, S. J., Brydges, R., Hatala, R., Zendejas, B., \& Cook, D. A. (2014). Reconsidering fidelity in simulation-based training. Academic Medicine, 89(3), 387-392.

Hill, A. E., Davidson, B. J., \& Theodoros, D. G. (2010). A review of standardized patients in clinical education: Implications for speech-language pathology programs. International Journal of Speech-Language Pathology, 12(3), 259-270.

Hill, A. E., Davidson, B. J., \& Theodoros, D. G. (2013a). Speech-language pathology students' perceptions of a standardised patient clinic. Journal of Allied Health, 42(2), 84-91B.

Hill, A. E., Davidson, B. J., \& Theodoros, D. G. (2013b). The performance of standardized patients in portraying clinical scenarios in speech-language therapy. International Journal of Language \& Communication Disorders, 48(6), 613-624.

Lubinski, R., \& Golper, L. A. C. (2007). Professional issues: From roots to reality. In R. Lubinski, L.C. Golper, \& C.M. Frattali (Eds.), Professional Issues in Speech-Language Pathology and Audiology, (pp. 3-45). New York, NY: Thomson Delmar Learning.

MacBean, N., Theodoros, D., Davidson, B., \& Hill, A. E. (2013). Simulated learning environments in speech-language pathology: An Australian response. International Journal of Speech-Language Pathology, 15(3), 345-357.

Marshall, S., Harrison, J., \& Flanagan, B. (2009). The teaching of a structured tool improves the clarity and content of interprofessional clinical communication. Quality and Safety in Health Care, 18(2), 137-140.

Miolo, G., \& DeVore, S. (2016). Speech language pathology and education students engage in interprofessional collaborative practice to support children with special needs in preschool settings. Journal of Interprofessional Education \& Practice, 4, 81-87.

Nagendran, A., Pillat, R., Kavanaugh, A., Welch, G., \& Hughes, C. (2014). A unified framework for individualized avatar-based interactions. Presence: Teleoperators and Virtual Environments, 23(2), 109-132.

Newton, J., Billet, S., Jolly, B., \& Ockerby, C. (2009). Lost in translation: Barriers to learning in health professional clinical education. Learning in Health and Social Care, 8(4), 315327.

Ohtake, P. J., Lazarus, M., Schillo, R., \& Rosen, M. (2013). Simulation experience enhances physical therapist student confidence in managing a patient in the critical care environment. Physical Therapy, 93(2), 216-228.

Picou, E., \& Tharpe, A. M. (2015). Standardized patients: Potential to improve student training in aural rehabilitation. SIG 8 Perspectives on Public Health Issues Related to Hearing and Balance, 16(1), 4-14.

Rodger, S., Webb, G., Devitt, L., Gilbert, J., Wrightson, P., \& McMeeken, J. (2008). Clinical education and practice placements in the allied health professions: An international perspective. Journal of Allied Health, 37(1), 53-62.

Strang, H. R., \& Meyers, S. C. (1987). A microcomputer simulation to evaluate and train effective intervention techniques in listening partners of preschool stutterers. Journal of 
Fluency Disorders, 12(3), 205-215.

Straub, C., Dieker, L., Hynes, M., \& Hughes, C. (2014). Using virtual rehearsal in TLE TeachLivE ${ }^{\mathrm{TM}}$ mixed reality classroom simulator to determine the effects on the performance of mathematics teachers. TeachLivE ${ }^{\mathrm{TM}}$ National Research Project: Year 1 Findings, 1-50.

Straub, C., Dieker, L., Hynes, M., \& Hughes, C. (2015). Using virtual rehearsal in TLE TeachLivE ${ }^{\mathrm{TM}}$ mixed reality classroom simulator to determine the effects on the performance of science teachers: A follow-up study (year 2). TeachLivE ${ }^{\mathrm{TM}}$ National Research Project: Year 2 Findings, 1-64.

Straub, C., Dieker, L., Hynes, M., \& Hughes, C. (2016). TLE TeachLivETM year 3 report. TeachLivE ${ }^{\mathrm{TM}}$ National Research Project: Year 3 Findings, 1-27.

Suleman, S., McFarlane, L. A., Pollock, K., Schneider, P., Leroy, C., \& Skoczylas, M. (2014). Collaboration: More than" Working Together" An exploratory study to determine effect of interprofessional education on awareness and application of models of specialized service delivery by student speech-language pathologists and teachers. Canadian Journal of Speech-Language Pathology \& Audiology, 37(4), 298-307.

Tarnowski, K. J., \& Simonian, S. J. (1992). Assessing treatment acceptance: The abbreviated acceptability rating profile. Journal of Behavior Therapy and Experimental Psychiatry, 23(2), 101-106.

Taylor, M.S., Tucker, J., Donehower, C., Pabian, P., Dieker, L.A., Hynes, M.C., \& Hughes, C. (2017). Impact of virtual simulation on the interprofessional communication skills of physical therapy students. Journal of Physical Therapy Education, 32(3), 149-159.

Trentham, B., Andreoli, A., Boaro, N., Velji, K., \& Fancott, C. (2010). SBAR: A shared structure for effective team communication. An implementation toolkit. 2nd Edition. Toronto Rehabilitation Institute: Toronto.

Vasquez III, E., Marino, M. T., Donehower, C., \& Koch, A. (2017). Functional analysis in virtual environments. Rural Special Education Quarterly, 36(1), 17-24.

Verlinde, E., De Laender, N., De Maesschalck, S., Deveugele, M., \& Willems, S. (2012). The social gradient in doctor-patient communication. International Journal for Equity in Health, 11(1), 12.

Williams, S. (2006). The Virtual Immersion Center for Simulation Research: Interactive simulation technology for communication disorders. In Presence-2006: Proceedings of the 9th Annual International Workshop (24-26 August 2006, Cleveland, Ohio).

Williams, S. (2009). Cutting edge graduate education: Developing clinical skills through simulated patients. Presentation at the American Speech-Language-Hearing Association Annual Convention. New Orleans, LA.

Williams, S., \& Schreiber, L. R. (2010). Beyond the big screen: Avatars prepare graduate students for real-world practice. SIG 16 Perspectives on School-Based Issues, 11(2), 5055.

Zraick, R. I. (2012). Review of the use of standardized patients in speech-language pathology clinical education. International Journal of Therapy and Rehabilitation, 19(2), 112-118.

Zraick, R. I., Allen, R. M., \& Johnson, S. B. (2003). The use of standardized patients to teach and test interpersonal and communication skills with students in speech-language pathology. Advances in Health Sciences Education, 8(3), 237-248. 
Appendix A. Case study provided to student participants

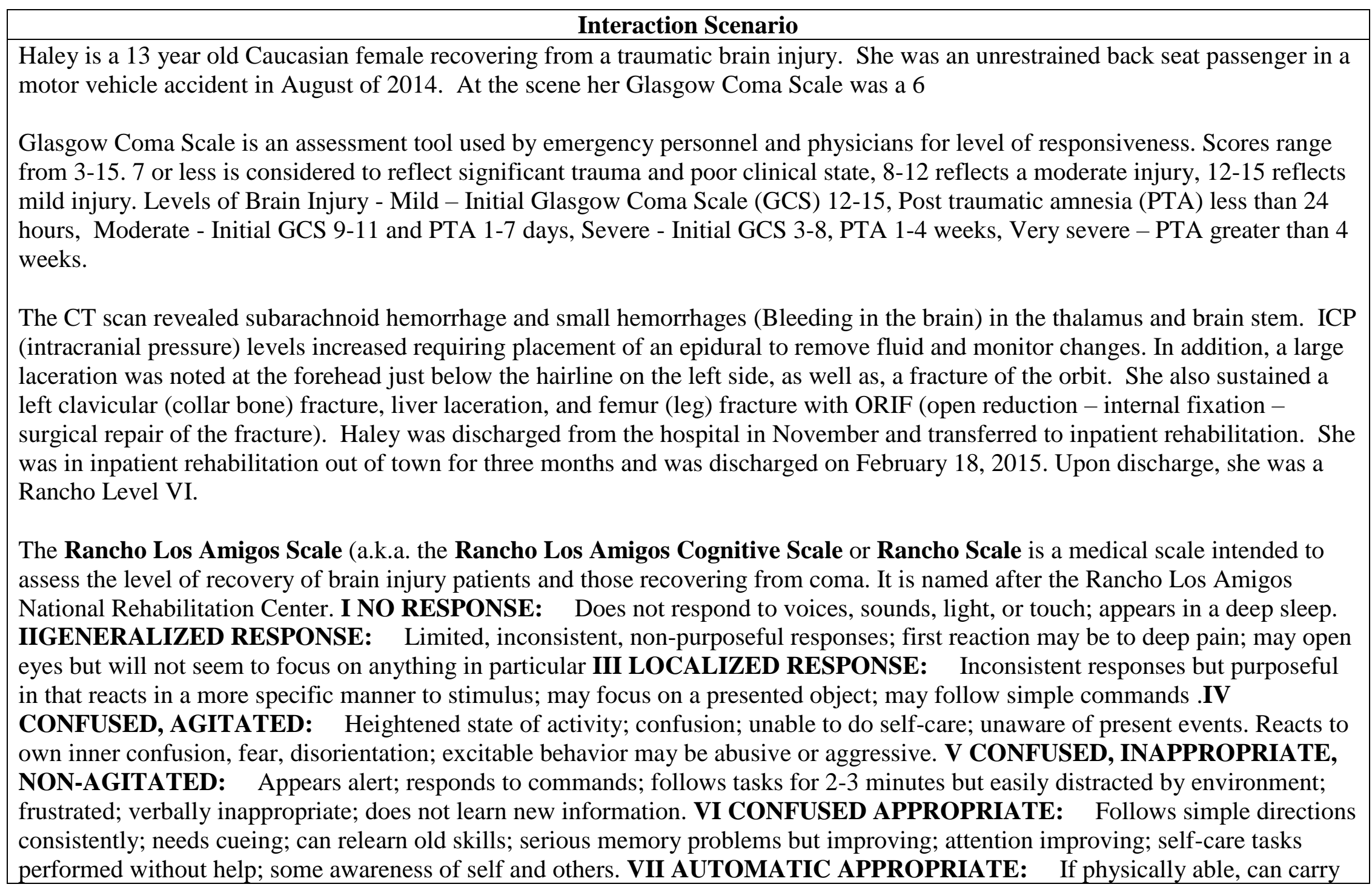


out routine activities but may have robot-like behavior, minimal confusion, shallow recall; poor insight into condition; initiates tasks but needs structure; poor judgement, problem-solving and planning skills; overall appears normal. VIII PURPOSEFUL

APPROPRIATE: Alert, oriented; recalls and integrates past events; learns new activities and can continue without supervision; independent in home and living skills; capable of driving; defects in stress tolerance, judgment; abstract reasoning persist; many function at reduced levels in society

Haley was referred to outpatient services including physical, occupation, and speech therapy. A referral was made to the school system for reentry to the public school system requiring exceptional education services. Neuropsychological testing reveals an IQ score of 80 with speech and language deficits noted. Haley is quiet and shy. Her functional deficits include: 1) decreased executive functioning (reasoning, problem solving. planning), flat affect (facial expression) 2) decreased response time and processing speed 3) difficulty with social interactions 4) decreased initiation 5) decreased coordination - unable to complete finger opposition (finger to finger, fine motor movements) or heel to shin (coordination in legs) 6) decreased dynamic sitting balance (reaching out of base of support while sitting) 7) decreased static standing balance with eyes closed 8) decreased dynamic balance - frequent LOB (loss of balance) with perturbations with difficulty recovering, high risk for falls 9) mild spasticity in L hamstrings, L adductors, and L gastroc/soleus (muscles in the leg) 10) abnormal gait (walk) - slow cadence (speed), decreased BOS (base of support), decreased hip flexion on L, lack of full knee extension on L, lack of ankle dorsiflexion on L 11) difficulty with fine motor skills particularly tripod grasp, handwriting, buttons, and zippers.

PMH (Previous medical history)- unremarkable

Social History - Prior to the accident, Haley was in $8^{\text {th }}$ grade honors classes and an A student. She participated in band, Junior National Honor Society, volleyball, and her church youth group. Haley has a supportive family consisting with both parents and a younger sister (10years old living in the home). Father has an advanced degree in marine biology and works for SeaWorld. Mother is a CPA and works full time in a local firm. Both parents have used FMLA and are now returning to work. Mother has reduced her hours to accommodate scheduling needs for therapies. Strengths: pleasant, polite, willingness to try, well behaved. Weaknesses: poor balance, poor coordination, decreased cognitive functioning, poor social skills, poor dexterity, monotone voice, difficulty with fine motor activities

Parents goals - To have Haley return to school and as normal of a routine as possible 


\section{Appendix B. Interactor Guidelines}

Participant Prompt: "Please share with Haley's parent your recommendations for speech-language therapy services in the school."

Scenario 1: Speech-language therapist needs to advise family that Haley will receive speech-language therapy to address social and attention deficits twice weekly in a group, pull-out model. Parent response demonstrates a lack of insight into deficits. Parent is unclear on why Haley would receive therapy in a group and is wondering how the SLP can work on social skills.

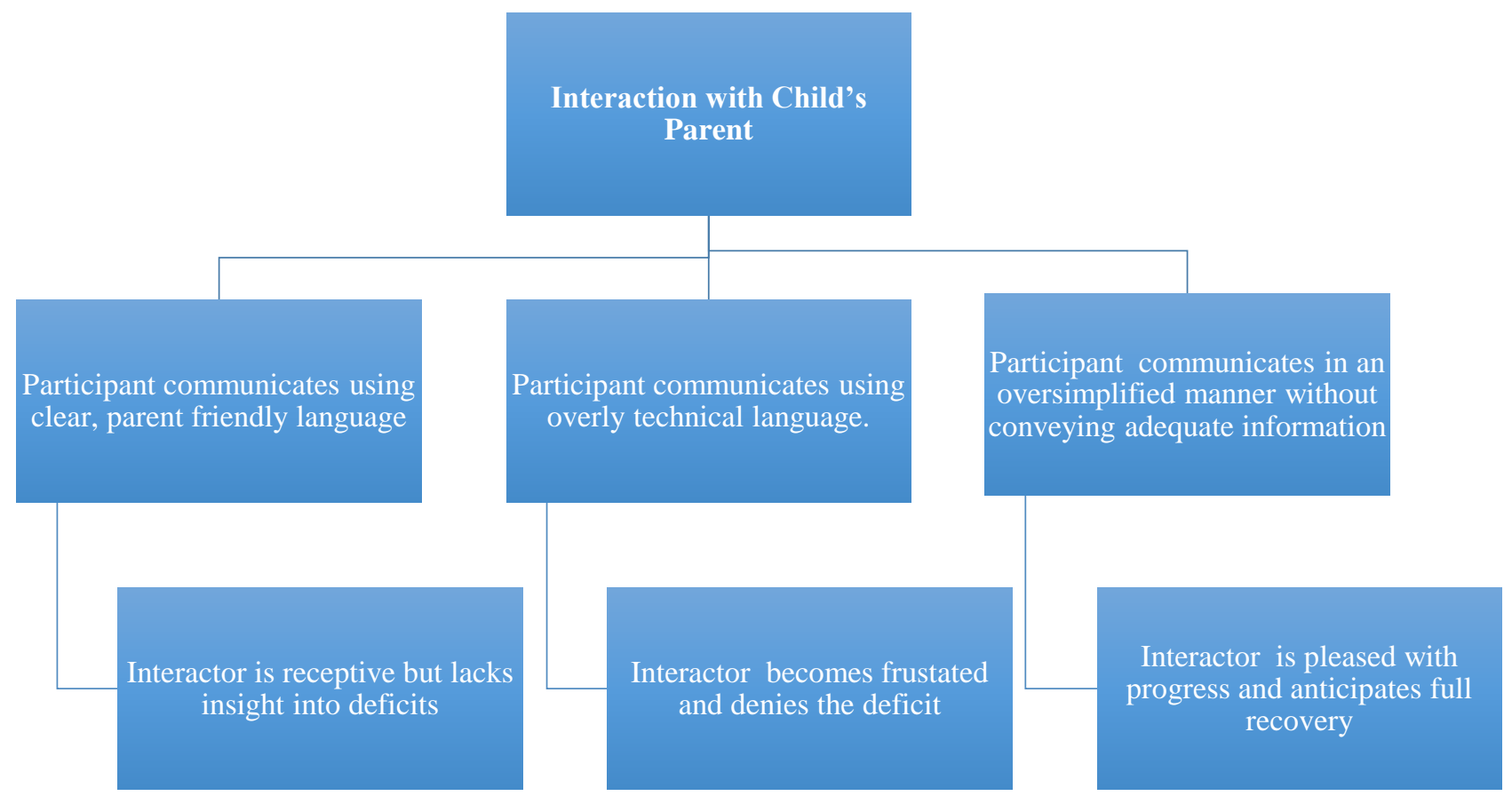

Participant Prompt: "Please share with Haley's teacher your recommendations for the classroom." 
Scenario 2: Speech-language therapist needs to convey to teacher that it would be most beneficial for Haley to receive speechlanguage therapy twice weekly in a group, pull-out model and request that Haley have preferential seating in the classroom for her attention deficits. Teacher response is one of concern. The teacher is uncertain that she can work to schedule Haley missing academic instruction twice a week. She is also concerned about how to give Haley preferential seating since she does not always teach from the front of the classroom.

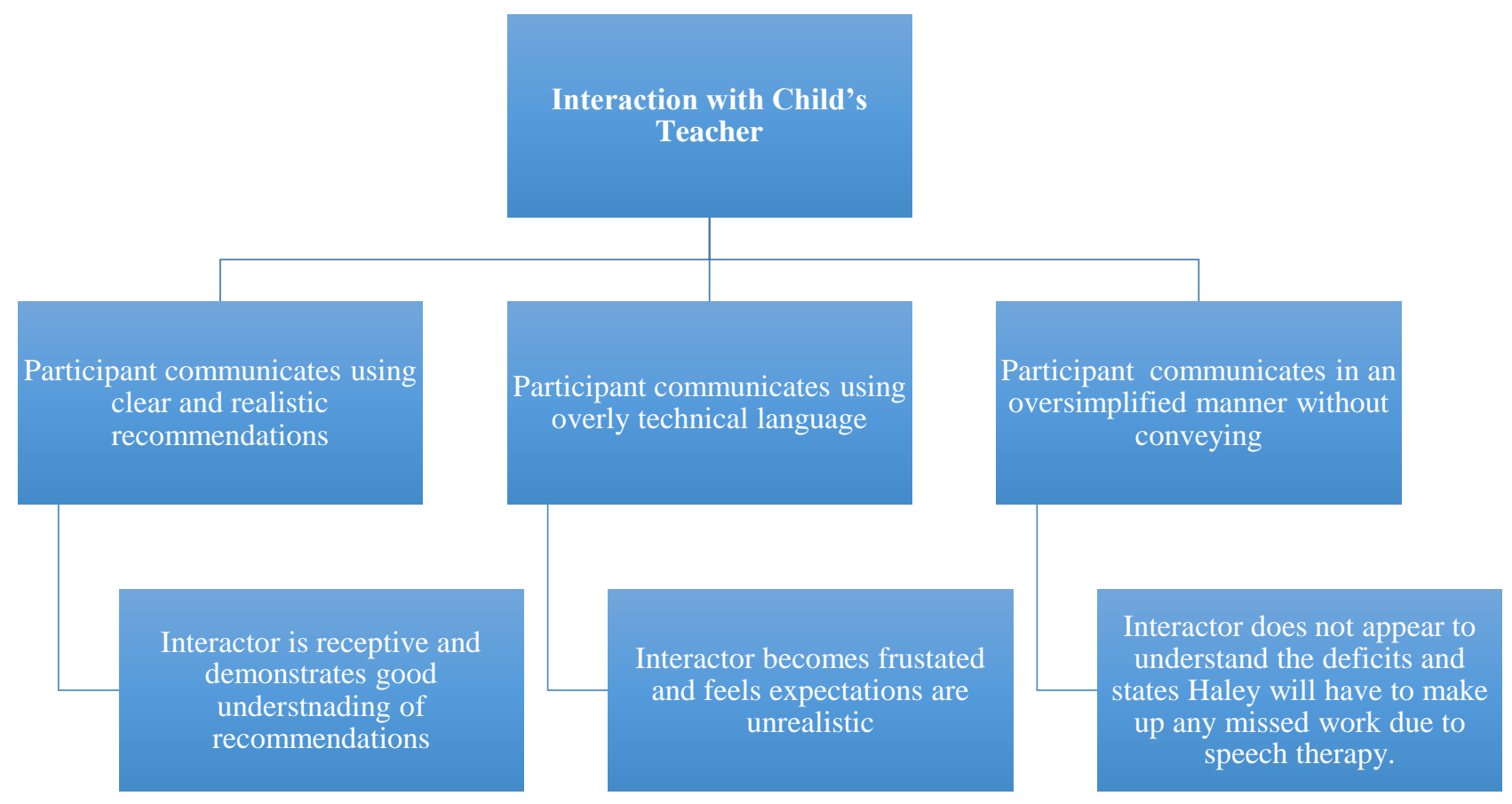

Participant Prompt: "Please share with Haley's pediatrician your concerns with Haley's recent change in dosage and timing of her medications and how it may impact school performance." 
Scenario 3: Interaction with Pediatrician - Speech-language therapist has contacted the pediatrician regarding Haley's recent change in dosage and timing of medication. SLP is concerned about the side effects of drowsiness during academic instruction in school. Pediatrician responds that it is the parents decision when to time the doses of Haley's medication.

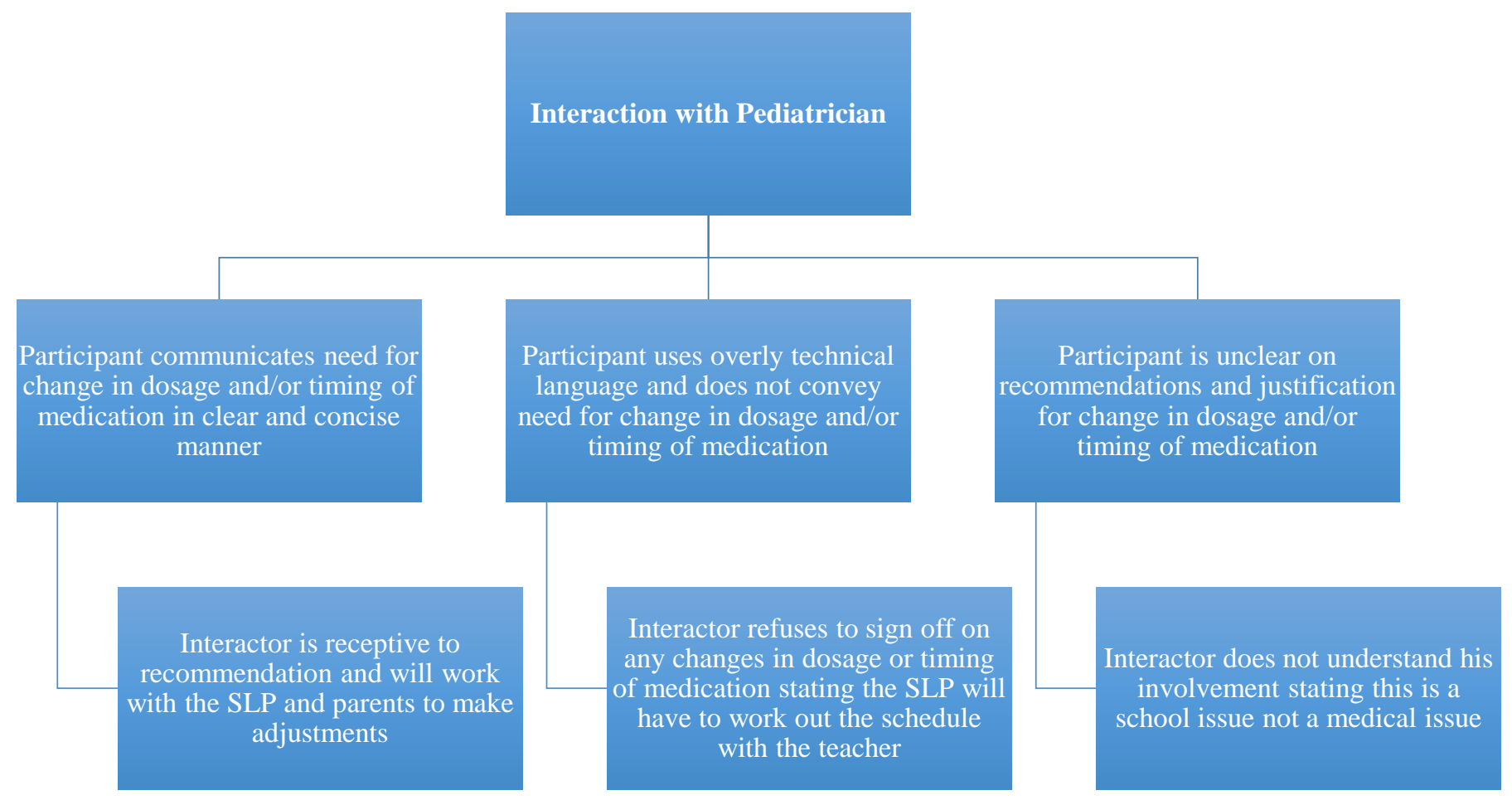


Appendix C. Situation, Background, Assessment, Recommendation, and Communication Tool

\section{Situation, Background, Assessment, Recommendation, and Communication Tool}

SBAR-C

Participant Number:

Date:

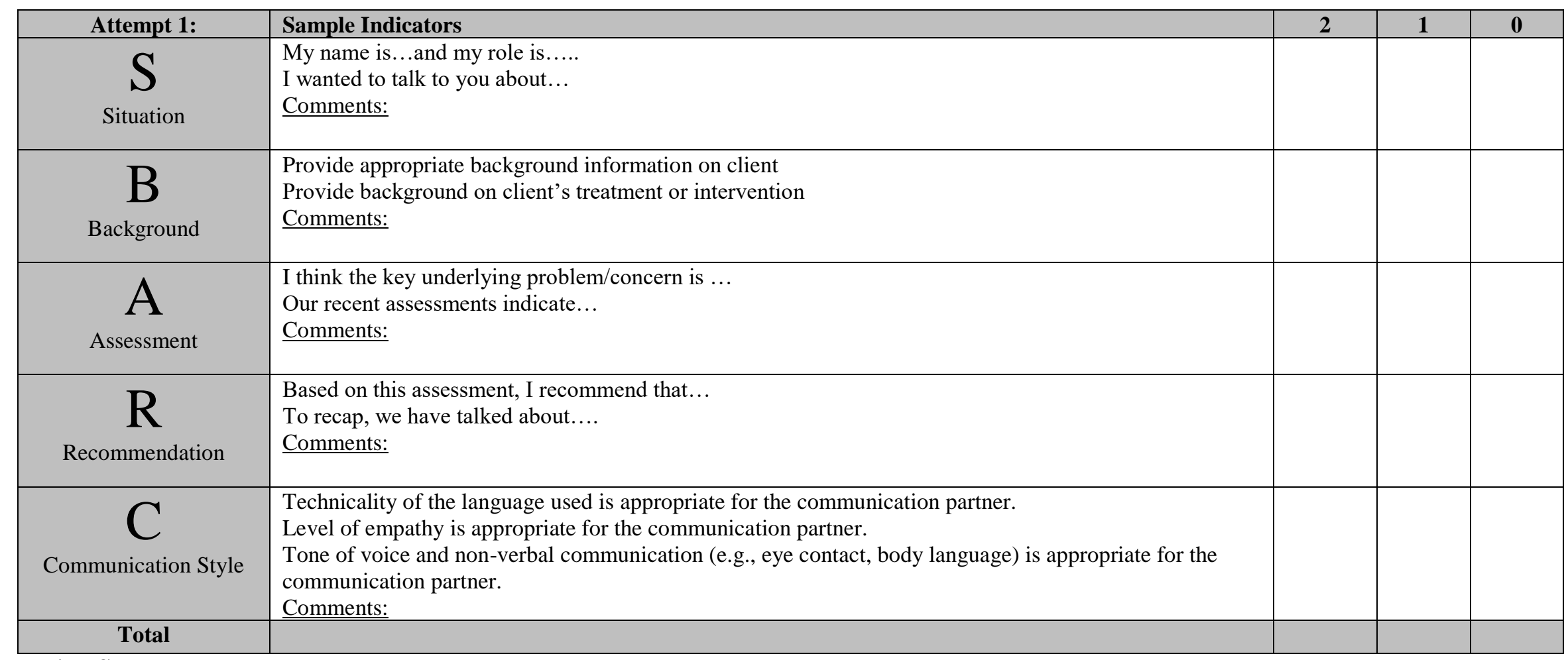

\section{Rating Scale}

\begin{tabular}{|c|l|}
\hline 2 & Behavior mostly or fully evident \\
\hline 1 & Behavior partially evident \\
\hline 0 & Behavior not evident \\
\hline
\end{tabular}

This SBAR tool was developed by Kaiser Permanente. Please feel free to use and reproduce these materials in the spirit of patient safety, and please retain this footer in the spirit of appropriate recognition.

\section{Scorer Name:}

Communication Partner: Parent/Teacher/Physician 
Appendix D. Abbreviated Acceptability Rating Profile - Modified

Abbreviated Acceptability Rating Profile - Modified

(Tarnowski \& Simonian, 1992)

Based on your experience with the TeachLivE simulator (i.e., virtual simulator, interaction with avatars) and the coaching you received during your session, please rate your experience below using the 6 point scale.

\begin{tabular}{|c|c|c|c|c|c|c|}
\hline & 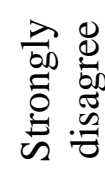 & 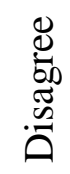 & 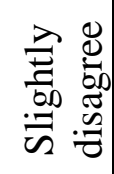 & 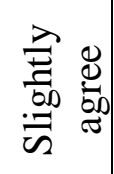 & 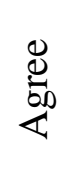 & 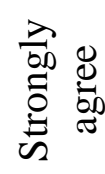 \\
\hline $\begin{array}{l}\text { 1. This is an acceptable teaching strategy for } \\
\text { professional communication. }\end{array}$ & 1 & 2 & 3 & 4 & 5 & 6 \\
\hline $\begin{array}{l}\text { 2. This teaching strategy should be effective in } \\
\text { changing my professional communication skills. }\end{array}$ & 1 & 2 & 3 & 4 & 5 & 6 \\
\hline $\begin{array}{l}\text { 3. I would be willing to participate in this teaching } \\
\text { strategy in the future. }\end{array}$ & 1 & 2 & 3 & 4 & 5 & 6 \\
\hline $\begin{array}{l}\text { 4. This teaching strategy will not have any negative } \\
\text { side effects. }\end{array}$ & 1 & 2 & 3 & 4 & 5 & 6 \\
\hline 5. I like using this teaching strategy. & 1 & 2 & 3 & 4 & 5 & 6 \\
\hline $\begin{array}{l}\text { 6. This strategy is a good way to teach professional } \\
\text { communication. }\end{array}$ & 1 & 2 & 3 & 4 & 5 & 6 \\
\hline 7. Overall, the teaching strategy will help me. & 1 & 2 & 3 & 4 & 5 & 6 \\
\hline
\end{tabular}

